\title{
Metabolism of 2,3,4,6-Tetrachlorophenol by Micro-organisms from Broiler House Litter
}

\author{
By JENNIFER M. GEE AND J. L. PEEL \\ Agricultural Research Council, Food Research Institute, Norwich NR4 7 UA
}

(Received 20 May 1974; revised I6 July 1974)

\begin{abstract}
SUMMARY
Isolates of 26 fungal species from broiler house litter were screened for their ability to metabolize and methylate 2,3,4,6-tetrachlorophenol over a five-day period, by adding the chlorophenol to cultures after mycelial pellets were established on a complete growth medium. Under these conditions, 99 of the I I 6 isolates tested metabolized the chlorophenol and 68 of these produced 2,3,4,6-tetrachloroanisole. The proportion of the chlorophenol methylated to the chloroanisole differed widely with the isolate, even within species. The highest methylation was observed with Penicillium corylophilum; certain other isolates, notably of $\boldsymbol{P}$. brevicompactum, metabolized almost all the chlorophenol without forming the chloroanisole. Progress studies with these species suggested that there is more than one route for the metabolism of 2,3,4,6-tetrachlorophenol. In tests with suspensions of mixed bacterial populations from broiler house litter, the chlorophenol was metabolized but no methylation was detected.
\end{abstract}

\section{INTRODUCTION}

It has been shown that $2,3,4,6$-tetrachloroanisole is a cause of musty taint in chickens, and that it is formed in broiler house litter by the microbial methylation of 2,3,4,6-tetrachlorophenol (Curtis et al. 1972, 1974). This chlorophenol, together with pentachlorophenol, is commonly present on the wood shavings that form the initial litter; by the end of the 8 to 9 week rearing cycle, these chlorophenols have almost disappeared (Parr et al. 1974). There is a transient accumulation of the corresponding chloroanisoles which reaches a maximum at 4 to 5 weeks (C. Dennis, D. G. Land, J. Mountford, and D. Robinson, unpublished). Micro-organisms may contribute to the loss of chlorophenols not only by methylation to give the volatile chloroanisoles but also by degradation via other metabolic routes. The microbial flora of broiler house litter has been studied with particular attention to the fungi present (Dennis \& Gee, I973), and some 33 different mould species have been isolated; of these the predominant organisms are species of Aspergillus, Penicillium and Scopulariopsis. The purpose of the experiments reported here was to establish whether the ability to metabolize chlorophenols is widespread among litter micro-organisms, and the extent to which it is associated with methylation.

\section{METHODS}

Experiments with fungi. The fungal isolates tested were those isolated from broiler house litter by Dennis \& Gee (1973); stock cultures were stored on slopes of Difco Bacto malt extract agar at $\mathrm{I}{ }^{\circ} \mathrm{C}$. To obtain spore suspensions for inocula, $\mathrm{I} \mathrm{ml}$ of sterile aqueous $0 . \mathrm{I} \%$ Tween 80 was added to a stock slope and, after shaking, approximately $0.2 \mathrm{ml}$ of the resulting 
suspension was spread evenly over a plate of Sabouraud dextrose agar pH 5.6 (Oxoid). The plate was then incubated at $25{ }^{\circ} \mathrm{C}$ until sporulation occurred ( 3 to 7 days according to the species). Discs, cut from the sporulating culture using a sterile cork borer, were shaken in a $28 \mathrm{~g}$ ( $\mathrm{I} \mathrm{oz}$ ) bottle containing $\mathrm{Io} \mathrm{ml}$ of the Tween 80 solution, and the resulting spore suspension pipetted off. Serial decimal dilutions in water were prepared for microscopic counts and the dilution containing between $10^{5}$ and $10^{6}$ spores $/ \mathrm{ml}$ was used for inoculation.

For tests on the metabolism of 2,3,4,6-tetrachlorophenol, the fungi were grown in $250 \mathrm{ml}$ Erlenmeyer flasks containing $20 \mathrm{ml}$ of Raulin-Thom (glucose-tartrate-mineral salts) medium as described by Clutterbuck, Oxford, Raistrick \& Smith (1932), except that the glucose concentration was $4 \%(\mathrm{w} / \mathrm{v})$. The medium was autoclaved at $103 \mathrm{kPa}\left(\mathrm{I} 5 \mathrm{lb} / \mathrm{in}^{2}\right)$ for I 5 min, and inoculated with $10^{5}$ spores. The cultures were grown at $25^{\circ} \mathrm{C}$ with orbital shaking until mycelial pellets were readily apparent; in several experiments where growth was measured, the minimum total dry weight was $20 \mathrm{mg}$. This required 3 to 9 days, depending on the species. At this point approximately $\mathrm{I} 20 \mu \mathrm{g}$ of 2,3,4,6-tetrachlorophenol were added aseptically, and the plastic foam plug hitherto closing the flask was replaced by a sterile plug consisting of a cork wrapped in aluminium foil and encircled with PTFE tape to prevent any loss of the volatile chloroanisole. The flasks were then shaken for a further 5 days before analysing the contents for the chlorophenol and chloroanisole. The $2,3,4,6-$ tetrachlorophenol (Fluka A. G., Buchs, Switzerland) was added as an aqueous $0 \cdot 1 \%$ solution of the sodium salt prepared by dissolving 2,3,4,6-tetrachlorophenol in $0 \cdot 1 \mathrm{~N}-\mathrm{NaOH}$, adding $\mathrm{H}_{3} \mathrm{PO}_{4}$ to $\mathrm{pH} 8 \cdot 0$, diluting to strength and sterilizing by filtration. The $2,3,4,6-$ tetrachlorophenol was purified by fractional vacuum sublimation; the resulting material contained approximately $2.5 \%(\mathrm{w} / \mathrm{w})$ of pentachlorophenol as an impurity. An uninoculated control was included with each batch of cultures. To follow the metabolism of the chlorophenol, replicate cultures were set up as above and the contents of one flask taken for analysis at each of the times indicated.

Experiments with bacteria. A mixed population of bacteria was obtained from broiler house litter taken four weeks after introduction of the birds. A sample (I00 g) of litter was homogenized with $\mathrm{I} 1$ Io mM-phosphate buffer $\mathrm{pH} 7 \cdot 4\left(\mathrm{NaH}_{2} \mathrm{PO}_{4}-\mathrm{Na}_{2} \mathrm{HPO}_{4}\right.$ mixture) in an Atomix blender (MSE) and filtered through a double layer of muslin to remove larger particles; this included virtually all the fungal mycelium. The filtrate was centrifuged at $500 \mathrm{~g}$ for to min, the pellet discarded and the process repeated. The supernatant from the second centrifugation was then centrifuged at $20000 \mathrm{~g}$ for $20 \mathrm{~min}$, the supernatant discarded and the pellet resuspended in the Io mM-phosphate buffer $\mathrm{pH} 7.4$ to give a final volume of $195 \mathrm{ml}$. The resulting suspension contained $8.5 \mathrm{mg}$ dry matter $/ \mathrm{ml}$ and microscopic examination showed it to be composed of bacteria, with no yeasts or mould fragments visible.

The freshly prepared bacterial suspension (IO $\mathrm{ml}$ ) was incubated with $25 \mu \mathrm{g} 2,3,4,6$ tetrachlorophenol for 5 days before analysis. In tests with the total litter homogenate, $20 \mathrm{ml}$ were incubated with $50 \mu \mathrm{g}$ of the chlorophenol in order to give a more suitable volume for shaking. Other details were as for the fungal experiments.

Determination of 2,3,4,6-tetrachlorophenol and 2,3,4,6-tetrachloroanisole. After incubation, the whole culture, including the mycelium or bacterial cells, was extracted by a continuous steam distillation/extraction technique, and the chlorophenol and chloroanisole then separated and estimated by gas-liquid chromatography, after first converting the chlorophenol to the corresponding ethyl ether (Gee, Land \& Robinson, 1974). These authors examined the recovery of chlorophenols and chloroanisoles from wood shavings and chicken tissues; their recoveries were not consistently quantitative and varied with the 
chlorophenol or chloroanisole and with the nature of the sample. In the present work, the samples analysed contained far less organic matter and tests showed that recoveries of 2,3,4,6-tetrachlorophenol were essentially quantitative. By contrast, the recoveries of 2,3,4,6-tetrachloroanisole were in the range 65 to $100 \%$; results for this compound have not been corrected and are therefore minimum values. None of the conclusions drawn would be invalidated by variations in recovery within the above range.

\section{RESULTS}

\section{Chlorophenol metabolism by pure cultures of fungi}

In the screening procedure adopted, the fungi were first allowed to grow in the absence of the chlorophenol because the concentration used inhibits both spore germination and the growth of some species in liquid culture. Because the flasks were sealed after the addition of the chlorophenol, conditions in the flasks may not have remained aerobic for the whole of the subsequent five-day incubation. This experimental limitation was accepted to allow a large number of isolates to be screened with simple apparatus.

Of the II 6 isolates tested, 99 were able to metabolize the chlorophenol (Table I) and only four species, Absidia cylindrospora, Aspergillus flavus, A. flavus var. columnaris and Mucor racemosus, showed little or no activity. With $A$. petrakii, A. repens, $A$. sydowi and Penicillium corylophilum almost complete metabolism was observed with most or all of the isolates tested. With most of the other species the amount of chlorophenol metabolized varied with the isolate, e.g. within the seven isolates of Scopulariopsis brevicaulis values ranged from $0 \%$ to $87 \%$.

Approximately two-thirds of the isolates that metabolized the chlorophenol produced greater than trace amounts of the 2,3,4,6-tetrachloroanisole. There were, however, wide differences between isolates in the proportion of the chlorophenol methylated. Penicillium corylophilum was the only species in which all the isolates examined showed a consistently high conversion. Isolates of the four species $A$. candidus, A. chevalieri, P. brevicompactum and $P$. chrysogenum gave little or no methylation, although several of these isolates metabolized most of the chlorophenol and two isolates of $P$. brevicompactum metabolized all of it.

The results obtained with 29 fungal isolates from litters associated with musty chickens showed no obvious divergence from the general pattern and in particular there was no evidence that these strains methylated more readily.

The above results were obtained after exposure of the fungi to the chlorophenol for a fixed period of five days. Where most of the chlorophenol disappeared without chloroanisole formation a transient accumulation of chloroanisole might have occurred at an earlier stage, and where a high methylation was observed there could have been subsequent metabolism of the chloroanisole. These possibilities were tested with $P$. brevicompactum USI 23 and $P$. corylophilum Usi6o, respectively. The former metabolized all of the chlorophenol within 8 days (Fig. I), and no chloroanisole was detected at any time before or after this period, suggesting that it is not formed when the chlorophenol is metabolized by this organism. With $P$. corylophilum most of the chlorophenol was metabolized within 2 days (Fig. I), and the remainder disappeared much more slowly. The maximum concentration of the chloroanisole was reached after 4 to 6 days; thereafter there was a marked decrease. These results suggest that there may be two different pathways for the utilization of this chlorophenol, only one of which involves methylation. 


\section{Table I. Metabolism of 2,3,4,6-tetrachlorophenol by fungal isolates}

Values for metabolism and methylation are given as percentages, on a molar basis, of the $2,3,4,6$ tetrachlorophenol added (98 to $137 \mu \mathrm{g}$, nominally $\mathrm{I} 20 \mu \mathrm{g}$ ). The chlorophenol metabolized was taken at the difference between the residual chlorophenol and that found in the uninoculated control. The figures for percentage methylation are minimum values as the recovery of the chloroanisole was not quantitative (see Methods).

Species

Absidia cylindrospora

Aspergillus amstelodami

A. candidus

A. chevalieri

A. chevalieri var, intermedius

A. clavatus

A. flavus

A. flavus var. columnaris

A. niger

A. petrakii

A. repens

A. restrictus

A. ruber
Isolate

CD5

CDII9

UD323

Us9o

USI I

UsI96

US28

USI $77 a$

M29*

USI 89

US46

S44*

Us78b

M33*

Us 66

US52

USIO

Us63

US50

USI 3

US264

F6I *

F44*

F $68^{*}$

US7I

Us67

US222

US77

UD33

UD2 15

CSI 4

UD3I 4

CSI42

CsI 80

L9*

LIO*

UDI 30

UD5I

Us35

S5I*

US3 I

US2I

T24*

USI 42

M40*

US22

USI 2

US98

LI 4 *

US43

US9I

LI 3*

Us97

USI 53
Percentage metabolized Percentage methylated

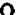

0

39

Tr

$\operatorname{Tr}$

$\mathrm{Tr}$

0

0

0

$\mathrm{Tr}$

o

3

I

I

$\mathrm{Tr}$

45

$\mathrm{Tr}$

6

2

2

$\mathrm{Tr}$

Tr

$\mathrm{Tr}$

0

0

0

2

3

4

0

3

40

44

48

$6 \mathrm{I}$

6I

25

74

45

64

27

0

30

3I

3

0

8

$\mathrm{Tr}$ 
Table r (continued)

Species

Aspergillus sydowi

A. versicolor

A. wentii

\section{Mucor racemosus}

Paecilomyces varioti

P. chrysogenum

P. corylophilum

P. crustosum

$P$. frequentans

P. roqueforti

Rhizopus oryzae

Scopulariopsis brevicaulis
Isolate

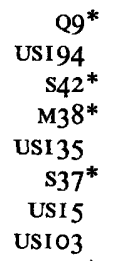

$$
\text { T2 I* }
$$

USI 84

Us61

USI 20

US228

M37*

M35*

s6o*

$\operatorname{CSI} 12$

UD27I

CD56

Usioo

CSI 8

CS2 1

Cs84

CSII

USI 23

CSI2Ib

Us62

CsIO9

USI 98

US49

US75

US72

USII 3

USI 62

Usi 60

USI 17

Us59

TI2*

RI3*

US20I

USI 85

L3*

S33*

USI 29

US52

CSI 27

US24

US30

CSI 2 Ia

CSI 26

CSI 29

CSI 58

CS97

CsI 55

D6*

USI 78

USI 7

USI

USI 7 I

T8*
Percentage metabolized Percentage methylated

100

$100 \quad 27$

$97-48$

$95 \quad 42$

92

$87-56$

$83-62$

$27-10$

$22 \quad 17$

$98 \quad 42$

$89 \quad 34$

$8 \mathrm{I} \quad 80$

$69-18$

$47-6$

$37 \quad 19$

9

30

$4 \quad \operatorname{Tr}$

o 0

$100-81$

$69 \quad 56$

$34 \quad 14$

I6 II

$100 \quad \mathrm{Tr}$

$97 \quad \mathrm{Tr}$

$28-0$

$\operatorname{Tr}$

o

Tr

o

80

62

83

75

2

3

Tr

I6

7

$\mathrm{I} 4$
6

$\operatorname{Tr}$

54

$\operatorname{Tr}$

0

65

27

8

7

$\operatorname{Tr}$

0

60

6

I

Tr

Tr

Tr, a definite trace but less than I $\%$.

* Isolate obtained from litter associated with musty chickens. 


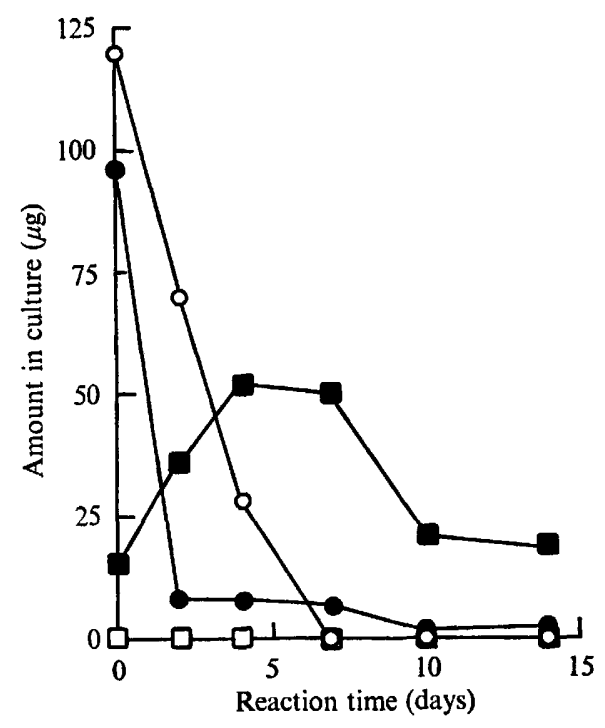

Fig. I. Metabolism of 2,3,4,6-tetrachlorophenol by Penicillium brevicompactum Us 23 and $P$. corylophilum usi6o. Replicate cultures were grown for 6 days at $25^{\circ} \mathrm{C}$ before addition of the chlorophenol at time 0 . A single culture was taken for analysis at each of the times indicated thereafter. O, 2,3,4,6-tetrachlorophenol in $\boldsymbol{P}$. brevicompactum culture; $\boldsymbol{O}, 2,3,4,6$-tetrachlorophenol in $\boldsymbol{P}$. corylophilum culture; $\square, 2,3,4,6$-tetrachloroanisole in $P$. brevicompactum culture; $\square, 2,3,4,6$ tetrachloroanisole in $P$. corylophilum culture.

\section{Chlorophenol metabolism by mixed bacterial populations}

When the chlorophenol was incubated with a mixed bacterial suspension from broiler house litter, it was completely metabolized within 5 days and no chloroanisole was detected. The total homogenate of poultry litter metabolized $85 \%$ of the chlorophenol in 5 days and produced a small but definite trace of chloroanisole. The formation of this chloroanisole was attributed to the presence of fungal fragments in the total homogenate. The effect of anaerobic conditions on the activity of this bacterial fraction was not tested, but in preliminary experiments, using mixed bacterial populations isolated from litter on a complex medium, no disappearance of the chlorophenol was observed under anaerobic conditions.

\section{DISCUSSION}

The methylation of 2,3,4,6-tetrachlorophenol by isolates of Aspergillus sydowi, Penicillium crustosum and Scopulariopsis brevicaulis has already been demonstrated (Curtis et al. 1972, I974) and the present results show that isolates from at least I 6 fungal species are able to carry out this methylation. Several isolates that we have regarded as giving a negative response in fact formed trace amounts of 2,3,4,6-tetrachloroanisole, and might well have been more active under appropriate conditions. Aspergillus sydowi, P. crustosum and $S$. brevicaulis methylate pentachlorophenol as well as the tetrachlorophenol (Curtis et al. 1972), and the same organisms also methylate 2,4,6-trichlorophenol (Gee, unpublished observations). The methylation of pentachlorophenol has also been reported with six species of Trichoderma (Cserjesi, 1972; Cserjesi \& Johnson, 1972), and with a Bacillus species from soil (Suzuki \& Nose, I97I). The ability to methylate highly-chlorinated phenols 
is not therefore restricted to a few organisms and, in particular, is widespread among the fungi of broiler house litters.

The ability to metabolize 2,3,4,6-tetrachlorophenol is even more widespread among the fungi tested than the ability to produce the chloroanisole. This chlorophenol was also metabolized without detectable methylation by mixed suspensions of bacteria from broiler house litter. There are several reports of the metabolism of pentachlorophenol by both fungi and bacteria (Ingols \& Stevenson, 1963; Chu \& Kirsch, 1972; Ide et al. 1972; Alliot, I973; Kirsch \& Etzel, I973), and of the 2,4,6-trichlorophenol by mixed bacterial cultures (Ingols, Gaffney \& Stevenson, 1966). Present evidence indicates that the removal of chlorophenols from broiler house litter, whether by methylation or otherwise, is due to microbial action. It involves many different species and probably more than one metabolic route.

We thank Mr M. G. Gee and Mr D. Robinson for advice on analytical techniques.

\section{REFERENCES}

Alliot, H. (1973). A bibliography of organic solvent-based wood preservatives. British Wood Preserving Association News Sheet No. 127.

CHU, J. P. \& KIRSCH, E. J. (I972). Metabolism of pentachlorophenol by axenic bacterial culture. Applied Microbiology 23, 1033-1035.

Clutterbuck, P. W., Oxford, A. E., Raistrick, H. \& Smith, G. (I932). Studies in the biochemistry of micro-organisms. XXIV. The metabolic products of the Penicillum brevicompactum series. Biochemical Journal, 26, I44I-I 458.

CSERJESI, A. J. (1972). Detoxification of chlorinated phenols. International Biodeterioration Bulletin 8 , $135-138$.

CSERJesi, A. J. \& Johnson, E. L. (1972). Methylation of pentachlorophenol by Trichoderma virgatum. Canadian Journal of Microbiology $\mathbf{1 8}, 45-49$.

Curtis, R. F., Land, D. G., Griffiths, N. M., Gee, M. G., Robinson, D., Peel, J. L., Dennis, C. \& Gee, J. M. (1972). 2,3,4,6-Tetrachloroanisole; association with musty taint in chickens and microbiological formation. Nature, London 235, 223-224.

Curtis, R. F., Dennis, C., Gee, J. M., Gee, M. G., Griffiths, N. M., Land, D. G., Peel, J. L. \& Robinson, D. (I974). Chloroanisoles as a cause of musty taint in chickens and their microbiological formation from chlorophenols in broiler house litters. Journal of the Science of Food and Agriculture 25, 8I I-828.

Dennis, C. \& GEE, J. M. (1973). The microbial flora of broiler-house litter and dust. Journal of General Microbiology 78, $101-107$.

GEe, M. G., LAND, D. G. \& RoBinson, D. (I974). Simultaneous analysis of chloroanisoles and chlorophenols. Journal of the Science of Food and Agriculture 25, 829-834.

Ide, A., Niki, Y., Sakamoto, F., Watanabe, I. \& Watanabe, H. (I972). Decomposition of pentachlorophenol in paddy soil. Agricultural and Biological Chemistry 36, 1937-1944.

Ingols, R. S. \& Stevenson, P. C. (1963). Degradation of the carbon chlorine bond. Research Engineering I8, 4-8.

Ingols, R. S., GAFFney, P. E. \& Stevenson, P. C. (I966). Biological activity of halophenols. Journal of the Water Pollution Control Federation 38, 629-635.

Kirsch, E. J. \& ETzel, J. E. (I973). Microbial decomposition of pentachlorophenol. Journal of the Water Pollution Control Federation 45, 359-364.

Parr, L. J., Gee, M. G., Land, D. G., Robinson, D. \& Curtis, R. F. (1974). Chlorophenols from wood preservatives in broiler house litter. Journal of the Science of Food and Agriculture 25, 835-84I.

SuzUKI, T. \& Nose, K. (I97I). Decomposition of pentachlorophenol in farm soil. II. Pentachlorophenol metabolism by a micro-organism isolated from soil. Noyaku Seisan Gijutsu 26, 2 I-24. 